\title{
CORRELATION AND PATH COEFFICIENT ANALYSIS IN ADVANCED WHEAT GENOTYPES
}

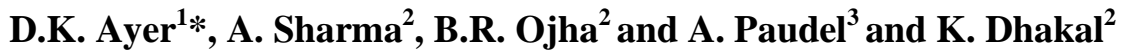 \\ ${ }^{1}$ Department of Genetics and Plant Breeding, N.M. College of Agriculture, Navsari Agricultural University, India \\ ${ }^{2}$ Department of Genetics and Plant Breeding, Agriculture and Forestry University, Nepal \\ ${ }^{3}$ Department of Genetics and Plant Breeding, Institute of Agriculture and Animal Science (IAAS) \\ Tribhuvan University (TU), Nepal
}

\begin{abstract}
A field experiment was conducted in alpha lattice design in subtropical region of $\mathrm{Nepal}$ in the wheat crop to determine the association between yield and yield attributing traits through correlation and path analysis. The result showed highly significant variations among the genotypes for all the traits under study. Simple correlation coefficients revealed that the association of grain yield with biological yield followed by harvest index, plant height, thousand grain weight and Area Under SPAD Retread Curve (AUSRC) at anthesis were positive and highly significant (at 1\% level of significance). The positive and significant (at 5\% level of significance) association of grains per spike followed by flag leaf area with grain yield was also found. Path analysis showed that biological yield and harvest index had the highest positive direct effect on grain yield. While other traits contribute to the grain yield significantly indirectly via biological yield and harvest index. This suggests that biological yield and harvest index having significant positive correlation and high direct effect on grain yield explained the true relationship and the direct selection of the genotypes through these traits is effective for improving yield potentiality.
\end{abstract}

Keywords: Correlation, genotypes, path analysis, selection, traits, wheat

\section{INTRODUCTION}

Wheat (Triticum aestivum L.) is the third most important staple food crop both in terms of area and production after rice and maize in Nepal with yield potential of $2.49 \mathrm{t} \mathrm{ha}^{-1}$ (MoAD, 2014). This yield is far below than the most wheat producing countries of the world and is not sufficient to fulfill the demands of growing population of Nepal. To minimize the prevalent yield gap and to provide food security in developing countries like Nepal, major efforts of wheat breeders have been directed towards improving its grain yield and development of varieties which

*Corresponding author email: dip_ayer@hotmail.com, ayerdk@gmail.com 
are high yielding and adaptable to wide range of environment. Chhibber and Jain (2014) reported that the traits affecting and influencing yield needs to be identified and selection has to be exerted on those characters which show a close association with grain yield. In agronomic and breeding studies, correlation coefficients are generally employed to determine the relation of grain yield and yield components. Simple correlation coefficients revealed that thousand-grain weight, number of grains per spike, and plant height showed significant positive correlations with grain yield (Reza et al., 2014) days to maturity had significant positive correlation with spike length and biological yield and grain yield (Gelalcha and Hanchinal, 2013), grain yield had positive correlation with peduncle length, spike length, grains per spike and 1000-grain weight, whereas, negative correlation with days to heading, plant height and tillers per plant (Iftikhar et al., 2012). Mohammadi et al. (2012), Tsegaye et al. (2012) and Zafarnaderi et al. (2013) also reported negative relationship between days to flowering and grain yield per plant in their studies in advanced wheat lines.

Ali and Shakor (2012), Anwar et al. (2009) and Bhutta et al. (2005) also reported that estimation of the correlation between yield and its components alone is not sufficient to understand the importance of each one of these components in determining the grain yield. Path coefficient analysis provides more information among variables than do correlation coefficients since this analysis provides the direct effects of specific yield components on yield and indirect effects via other yield components (Arshad et al., 2006, Del Moral et al., 2003). In agriculture, path analyses have been used by plant breeders to assist in identifying traits that are useful as selection criteria to improve crop yield (Dewey and Lu, 1959, Milligan et al., 1990). A study on path analysis, Iftikhar et al. (2012), indicated that 1000-grain weight had the highest positive direct effect on yield followed by spike length and days to heading while, plant height, grains per spike and peduncle length had negative direct effect on yield. So, these results suggested that traits such as spike length and 1000-grain weight having positive correlation and direct effect on grain yield can be used as suitable selection criteria to develop high yielding genotypes. The purpose of this study, therefore, was to estimate correlation between yields and yield attributing traits as well as the direct and indirect effects of these component traits on yield. The information so derived could be exploited in devising further breeding strategies and selection procedures to develop new varieties of wheat with high yield potentiality.

\section{MATERIALS AND METHODS}

\section{Field Experiment}

Fifty wheat genotypes including Gautam (a released variety) were investigated in the research field of the Institute of Agriculture and Animal Science (IAAS), Rampur Campus, Chitwan, Nepal in the normal growing season of 2014-2015. The soil type was sandy loam. The experiment was laid out in alpha lattice design with two replications. The plot size was $4 \mathrm{~m} . \mathrm{X} 1.5 \mathrm{~m} .=6 \mathrm{~m}^{2}$ each and row spacing in each 
plot for wheat sowing was $25 \mathrm{~cm}$. The spacing between two plots was $50 \mathrm{~cm}$ and inter spacing between two replications was $1 \mathrm{~m}$. Other recommended cultural practices for wheat production were applied during the growing season to raise a good crop.

\section{Data Recorded and Analysis}

Observations and measurements were recorded from five randomly selected plants per plot (excluding border plants) for each genotype separately for the following sixteen quantitative yield attributing traits: days to flag leaf emergence (DFL), days to booting (DB), days to heading (DH), days to anthesis (DA), flag leaf area (FLA), area under SPAD retread curve (AUSRC), days to flag leaf senescence (DFLS), days to maturity (DM), plant height (PH), spike length (SL), peduncle length (PL), grains per spike (GS), thousand grain weight (TGW), biological yield (BY), harvest index (HI) and grain yield (GY). DFL, DB, DH, DA, DF and DM were recorded based on the $50 \%$ population observation, FLA was recorded in $\mathrm{cm}^{2}$, DFLS was recorded as the date in which $50 \%$ of the flag leaves had lost their $90 \%$ green color and turned yellow, PH, SL, PL were measured in cm., TGW in grams, AUSRC with SPAD value and yield was converted to Kilograms per hectare for the analysis. Statistical analysis was carried out using Microsoft Office Excel 2013, R-studio (v. 0.99) and SPSS (v. 21). Analysis of Variance (ANOVA) for alpha lattice design was estimated by using methods suggested by Donner and Osman (2007).

\section{Correlation Coefficients}

\section{Days to flag leaf emergence vs grain yield}

Days to flag leaf emergence had non-significant but negative correlation with grain yield. Days to flag leaf emergence had highly significant and positive correlation with days to anthesis followed by days to heading, days to booting, days to maturity, days to flag leaf senescence. It had highly significant negative correlation with 1000 grain weight followed by HI, FLA and peduncle length.

\section{Days to booting vs grain yield}

Days to booting had non-significant and negative correlation with grain yield. It had highly significant and positive correlation with days to anthesis followed by days to heading, days to maturity and days to flag leaf senescence. It exhibited highly significant negative correlation with 1000 grain weight followed by HI. It had significant negative correlation with flag leaf area.

\section{Days to heading vs grain yield}

It showed non-significant and negative correlation with grain yield. It exhibited highly significant and positive correlation with days to anthesis followed by days to maturity, and days to flag leaf senescence. It had highly significant negative correlation with harvest index. It showed significant but negative correlation with thousand grain weight. 
D.K. Ayer et al.

\section{Days to anthesis vs grain yield}

It exhibited non-significant but negative correlation with grain yield. It had highly significant positive correlation with days to maturity followed by days to flag leaf senescence. It showed highly significant negative correlation with 1000 grain weight followed by HI and FLA. It showed significant positive correlation with AUSRC at anthesis followed by spike length. It indicated significant negative correlation with peduncle length.

\section{Flag leaf area vs grain yield}

FLA exhibited significant positive correlation with grain yield. It had highly significant positive correlation with peduncle length followed by thousand grains weight and BY. It showed significant positive correlation with plant height.

\section{Area under SPAD retread curve (AUSRC) at anthesis vs grain yield}

AUSRC showed highly significant positive correlation with grain yield. It also showed highly significant positive association with GS followed by BY. It had significant positive correlation with days to flag leaf senescence followed by plant height and days to maturity.

\section{Days to flag leaf senescence vs grain yield}

Days to flag leaf senescence showed non-significant and positive correlation with grain yield. It had highly significant and positive correlation with DM followed spike length, plant height and BY.

\section{Days to maturity vs grain yield}

Grain yield had non-significant negative correlation with DM. DM showed highly significant and positive correlation with spike length. It showed highly significant negative correlation with 1000 grain weight. It exhibited significant but negative correlation with $\mathrm{HI}$.

\section{Plant height vs grain yield}

Grain yield exhibited highly significant and positive correlation with plant height.PH had highly significant positive correlation with BY followed by peduncle length.

\section{Spike length vs grain yield}

Spike length showed positive correlation with grain yield. It had significant negative correlation with 1000 grain weight but non-significant positive correlation with grains per spike followed by peduncle length and BY.

\section{Peduncle length vs grain yield}

It indicated positive correlation with grain yield. It showed highly significant positive correlation with 1000 grain weight and significant positive correlation with biological yield. 


\section{Grains per spike vs grain yield}

It indicated significant positive correlation with grain yield. It showed significant positive correlation with BY. It showed positive correlation with $\mathrm{HI}$ and negative correlation with 1000 grain weight.

\section{Thousand grain weight vs grain yield}

It indicated highly significant positive correlation with grain yield. It exhibited significant positive correlation with $\mathrm{HI}$ and positive correlation with BY.

\section{Biological yield vs grain yield}

It exhibited the highest highly significant positive correlation with grain yield. It showed positive association with HI.

\section{Harvest index vs grain yield}

It indicated highly significant positive correlation with grain yield.

\section{Path Analysis}

In this paper, the results shown are interpreted for the values with low, moderate and high effects only.

\section{Direct effects on grain yield}

The highest (0.30-0.99) positive direct effect on grain yield was exhibited by biological yield (0.737) followed by harvest index $(0.555)$. The positive direct effect on grain yield was also exhibited by thousand grain weight $(0.072)$ followed by days to flag leaf emergence (0.063), days to maturity (0.054), days to booting (0.043), days to heading (0.032), flag leaf area (0.018) and grains per spike (0.010). While days to anthesis followed by AUSRC at anthesis, days to flag leaf senescence, plant height, spike length and peduncle length had negative direct effect on grain yield with the values of $-0.072,-0.044,-0.037,-0.028,-0.006$ and -0.006 respectively.

\section{Indirect effects on grain yield}

\section{Days to flag leaf emergence vs grain yield}

Days to flag leaf emergence exhibited positive direct effect on grain yield with value of 0.063 . It also showed moderate $(0.20-0.29)$ indirect negative effect on grain yield via harvest index (-0.242).

\section{Days to booting vs grain yield}

Days to booting exhibited negligible direct positive effect on grain yield (0.043) while days to booting showed moderate negative indirect effect on grain yield via harvest index $(-0.206)$.

\section{Days to heading vs grain yield}

Days to heading had positive direct effect (0.032) on grain yield. It also exhibited moderate negative indirect effect on grain yield via harvest index $(-0.209)$. 


\section{Days to anthesis vs grain yield}

Days to anthesis exhibited negative direct effect (-0.072) on grain yield. It also showed moderate negative indirect effect on grain yield via harvest index (-0.255).

\section{Flag leaf area vs grain yield}

Flag leaf area exhibited positive direct effect (0.018) on grain yield. It also had moderate positive indirect effect on grain yield via biological yield (0.274).

\section{AUSRC at anthesis vs grain yield}

AUSRC at anthesis (SPAD chlorophyll) had negative direct effect (-0.044) and had moderate positive indirect effect via biological yield (0.296) while low positive indirect effect via harvest index (0.106) on grain yield.

\section{Days to flag leaf senescence vs grain yield}

Days to flag leaf senescence exhibited negative direct effect (-0.037) and moderate positive indirect effect on grain yield via biological yield (0.274).

\section{Days to maturity vs grain yield}

Days to maturity showed positive direct effect (0.054) and low (0.10-0.19) negative indirect effect on grain yield via harvest index (-0.163).

\section{Plant height vs grain yield}

Plant height unveiled negative direct effect (-0.028) and had high (0.30-0.99) positive indirect effect on grain yield via biomass yield (0.412).

\section{Spike length vs grain yield}

Spike length revealed negative direct effect (-0.006) and low positive indirect effect on grain yield via biological yield (0.107).

\section{Peduncle length vs grain yield}

Peduncle length demonstrated negative direct effect $(-0.006)$ and moderate positive indirect effect via biological yield (0.227).

\section{Grains per spike vs grain yield}

Grains per spike exhibited positive direct effect $(0.010)$ and moderate positive indirect effect on grain yield via biological yield (0.238) and low positive indirect effect via HI (0.133).

\section{Thousand grain weight vs grain yield}

Thousand grain weights showed direct positive effect (0.072) and low positive indirect effect on grain yield via biological yield (0.166) and harvest index (0.193).

\section{Biological yield vs grain yield}

The highest (0.30-0.99) positive direct effect on grains per plant was exhibited by biological yield (0.737). 


\section{Harvest index vs grain yield}

The high positive direct effect of harvest index (0.555) on grain yield was exhibited.

\section{DISCUSSION}

There were significant differences among the genotypes for all characters reported here due to diverse genetic background of advanced wheat genotypes used in this experiment.

\section{Correlation and Path Analysis}

In the present research, for BY and $\mathrm{HI}$, highly significant and positive correlation was observed with grain yield with values of $0.836 * *$ and $0.700 * *$ respectively and the direct effects were also positive and highest with values of 0.737 and 0.555 respectively (Table $1 \& 2$ ). This suggests that there were little or no indirect effects of these traits on grain yield and whatever relationship existed with grain yield was direct. Singh and Chaudhary (1979) suggested that if the correlation coefficient between a causal factor and the effect is almost equal to its direct effect, the correlation explains the true relationship and the direct selection through these traits is effective. Therefore, these traits (BY and HI) could be used as selection criteria for improving wheat grain yield. Fellahi et al. (2013), Gelalcha and Hanchinal (2013), Tsegaye et al. (2012) also obtained similar result. This implies that selection of wheat genotypes on the basis of biomass yield and harvest index would be beneficial for increasing wheat grain yield.

The correlation coefficient of plant height $\left(0.390^{* *}\right)$, thousand grain weight $\left(0.386^{* *}\right)$ and AUSRC at anthesis $\left(0.372^{* *}\right)$ were also observed to be highly significant and positive with grain yield. The direct effects of these traits with values $-0.028,0.072,-0.044$ respectively indicated the negligible effect on grain yield (Table $1 \& 2$ ). Similar results for 1000 grain weight with grain yield were also found by Suleiman et al. (2014), significant positive correlation of plant height with grain yield by (Reza et al., 2014) and negative direct effect of plant height on grain yield by Iftikhar et al. (2012) and Suleiman et al. (2014). This indicates that indirect effect seems to be the cause of high correlation showing indirect positive effect through BY and $\mathrm{HI}$ on grain yield are the possible cause of positive correlation and negative direct effects are because of the negative indirect effects of the other traits, so these traits are to be considered simultaneously for the selection of wheat genotypes. These findings also tell that increase in thousand grain weight and AUSRC at anthesis increases the grain yield by increasing biomass yield and harvest index. So, while selection of the genotypes for higher grain yield through these traits, BY and HI 
Table1. Correlation coefficients of fifteen traits for grain yield in advanced wheat genotypes

\begin{tabular}{|c|c|c|c|c|c|c|c|c|c|c|c|c|c|c|c|c|}
\hline & DFL & DB & $\mathrm{DH}$ & DA & FLA & AUSRC & DFLS & $\mathrm{DM}$ & $\mathrm{PH}$ & SL & PL & GS & TGW & BY & $\mathrm{HI}$ & GY \\
\hline DFL & 1 & & & & & & & & & & & & & & & \\
\hline DB & $0.824^{* *}$ & 1 & & & & & & & & & & & & & & \\
\hline DA & $0.969^{* * *}$ & $0.844^{* *}$ & $0.841^{* *}$ & 1 & & & & & & & & & & & & \\
\hline FLA & $-0.433^{* *}$ & $-0.341^{*}$ & -0.263 & $-0.371^{* *}$ & 1 & & & & & & & & & & & \\
\hline AUSRC & 0.248 & 0.162 & 0.197 & $0.295^{*}$ & 0.164 & 1 & & & & & & & & & & \\
\hline $\mathrm{DM}$ & $0.753^{* *}$ & $0.551^{* *}$ & $0.702^{* *}$ & $0.751^{* *}$ & -0.093 & $0.289^{*}$ & $0.735^{* *}$ & 1 & & & & & & & & \\
\hline PH & 0.065 & 0.230 & 0.099 & 0.150 & $0.282^{*}$ & $0.301^{*}$ & $0.410^{* *}$ & 0.110 & 1 & & & & & & & \\
\hline SL & 0.238 & 0.240 & 0.086 & $0.294^{*}$ & 0.248 & 0.161 & $0.437^{* *}$ & $0.440^{* *}$ & 0.271 & 1 & & & & & & \\
\hline PL & $-0.380^{* *}$ & -0.161 & -0.230 & $-0.279^{*}$ & $0.644^{* *}$ & 0.116 & -0.038 & -0.218 & $0.544^{* *}$ & 0.145 & 1 & & & & & \\
\hline GS & 0.070 & 0.226 & 0.084 & 0.120 & 0.089 & $0.409^{* *}$ & 0.001 & 0.030 & 0.145 & 0.149 & 0.137 & 1 & & & & \\
\hline GY & -0.259 & -0.163 & -0.195 & -0.260 & $0.348^{*}$ & $0.372^{* *}$ & 0.184 & -0.075 & $0.390^{* *}$ & 0.077 & 0.236 & $0.361^{*}$ & $0.386^{* *}$ & $0.836^{* *}$ & $0.700^{* *}$ & 1 \\
\hline
\end{tabular}

*Means significance at $5 \%$ level, ** means significance at $1 \%$ level, without asterisk means non - significance at 5\% level. DFL=Days to Flag Leaf emergence, $\mathrm{DB}=$ Days to booting, $\mathrm{DH}=$ Days to heading, $\mathrm{DA}=$ Days to anthesis, FLA= Flag leaf area, AUSRC= Area under SPAD retread curve at anthesis, DFLS= Days to flag leaf senescence, $\mathrm{DM}=$ Days to maturity, $\mathrm{PH}=\mathrm{Plant}$ height, $\mathrm{SL}=\mathrm{Spike}$ length, $\mathrm{PL}=\mathrm{Peduncle}$ length, $\mathrm{GS}=\mathrm{Grains}$ per spike, TGW= Thousand grain weight, BY= Biological yield, HI= Harvest index, GY=Grain yield in kilograms per hectare. 
Table 2. Path Analysis Matrix of direct and indirect effects of fifteen traits on grain yield of advanced wheat genotypes



Residual effect: 0.0081 . Underlined numbers are positive direct effects (bold face), double underlined numbers are high in magnitude. Values in the off diagonal or columns show indirect effects on grain yield. DFL=Days to Flag Leaf emergence, $\mathrm{DB}=\mathrm{Days}$ to booting, $\mathrm{DH}=\mathrm{Days}$ to heading, $\mathrm{DA}=$ Days to anthesis, FLA= Flag leaf area, AUSRC= Area under SPAD retread curve at anthesis, DFLS= Days to flag leaf senescence, DM= Days to maturity, $\mathrm{PH}=$ Plant height, $\mathrm{SL}=$ Spike length, $\mathrm{PL}=$ Peduncle length, $\mathrm{GS}=$ Grains per spike, $\mathrm{TGW}=$ Thousand grain weight, $\mathrm{BY}=\mathrm{Biological}$ yield, $\mathrm{HI}=$ Harvest index, GY=Grain yield in kilogram per hectare. $($ High $=0.30-0.99$, Moderate $=0.20-0.29$, Low $=0.10-0.19)$ 
should also be considered simultaneously in selection. Grains per spike $\left(0.361^{*}\right)$ exhibited significant positive association with grain yield and also showed positive direct effect on grain yield with value of 0.010 which is negligible. This indicates that the positive and significant correlation of GS is due to the moderate positive indirect effect of the GS on grain yield through BY (0.238) and low positive indirect effect via HI (0.133). GS had positive and significant correlation with grain yield which was also reported by Gelalcha and Hanchinal (2013). Flag leaf area $\left(0.348^{*}\right)$ depicted significant and positive correlation and negligible direct effect (0.018) with grain yield but moderate positive indirect effect on grain yield via BY (0.274). This indicates that casual factor BY should be considered in selection if the selection is to be made through flag leaf area. This also indicates that higher the flag leaf area higher will be the grain yield. Suleiman et al. (2014) also revealed that leaf area index had negative direct effect on yield.

DFLS, SL and PL also showed positive correlation and negative direct effect on grain yield. It indicates that DFLS and PL contribute to grain yield indirectly moderately via BY and SL contribute with low indirect effect via BY. This indicates that these three traits also have importance in breeding of wheat and the genotypes with longer reproductive phase and longer spike length and peduncle length should be selected for wheat improvement. Hence, for selection breeding, indirect casual factor BY and other positively contributing factors should be considered if selection is made through DFLS, SL and PL. Similar correlation results for SL and PL were also revealed by Zafarnaderi et al. (2013).Negative direct effect of peduncle length on grain yield was also reported by Iftikhar et al. (2012). DFL, DB, DH and DM exhibited negative correlation with grain yield but negligible positive direct effect on grain yield. The negative correlation of DA and DH with gain yield was also reported by Mohammadi et al. (2012), Tsegaye et al. (2012) and Zafarnaderi et al. (2013). The negative correlation is due to the moderate negative indirect contribution of the DFL, DB and DH on grain yield via HI (-0.242. $-0.206,-0.209$ respectively) and that of DM via low indirect effect of HI (-0.163). Days to anthesis had negative correlation and negative direct effect on grain yield. The negative correlation is due to the negative indirect effect of DA on grain yield via HI (-0.255) and other negatively indirectly contributing factors indicating that the early maturing genotypes with longer reproductive phase are better for obtaining high grain yield. These traits indicating relatively non-significant correlation and negligible direct or indirect effect on grain yield are of relatively poor importance in selection breeding for increasing grain yield in these advanced wheat genotypes. Biological yield with flag leaf area, AUSRC at anthesis, days to flag leaf senescence and plant height, individually, showed highly significant and positive inter se association. Similarly, harvest index with days to flag leaf emergence, days to booting, days to heading and days to anthesis, individually, showed highly significant negative inter se association.

Therefore, while selection of the wheat genotypes for increasing grain yield, the yield attributing traits which shows significant correlation and exhibit positive 
direct and indirect effect with considerable magnitude on grain yield are to be considered in selection and are of importance in breeding strategies.

\section{CONCLUSION}

Correlation analysis results showed that the association of grain yield with biological yield followed by harvest index, plant height, thousand grain weight and AUSRC at anthesis were positive and highly significant whereas positive and significant with grains per spike and flag leaf area indicating that these traits were yield determinative traits. Besides, path analysis revealed that the biomass yield followed by harvest index had the highest positive direct effect on grain yield whereas high positive indirect effect of plant height and moderate positive indirect effects of AUSRC at anthesis, flag leaf area, days to flag leaf senescence, peduncle length and grains per spike on grain yield through biological yield. Strong correlation and positive direct effect of thousand grain weight with grain yield on the one hand and negative direct effect and strong correlation of plant height with grain yield revealed that the selection of these genotypes with high thousand grain weight and moderate plant height should be emphasized while selection for improving grain yield. Therefore, selection of wheat genotypes with high biological yield and high harvest index along with simultaneous consideration of moderate plant height and high thousand grain weight is a prerequisite for attaining improvement in wheat grain yield.

\section{ACKNOWLEDGEMENT}

This experimental work was supported by International Maizeand Wheat Improvement Centre (CIMMYT), Nepal and Nepal Agricultural Research Council (NARC) by providing the planting materials free of cost and deserve high appreciation. Technical assistance of Professor Bishnu Raj Ojha, Assist. Prof. Raju Kharel, Senior Scientist Dr. Dhruba Bahadur Thapa and Prof. Dr. Keshav Raj Adhikariare highly admired. All the helping hands from sowing to analysis and interpretation of data are acknowledged with appreciation.

\section{REFERENCES}

Ali, I. and Shakor, E. 2012. Heritability, variability, genetic correlation and path analysis for quantitative traits in durum and bread wheat under dry farming conditions. Mesoptamia Journal of Agriculture, Vol. 40 (4): 27-39

Anwar, J., Ali, M., Hussain, M., Sabir, W., Khan, M., Zulkiffal, M. and Abdullah, M. 2009. Assessment of yield criteria in bread wheat through correlation and path analysis. Journal of Animal and Plant Sciences, Vol. 19: 185-188

Arshad, M., Ali, N. and Ghafoor, A. 2006. Character correlation and path coefficient in soybean Glycine max (L.) Merrill. Pakistan Journal of Botany, Vol. 38 (1): 121

Bhutta, W. M., Akhtar, J., Anwar-ul-Haq, M. and Ibrahim, M. 2005. Cause and effect relations of yield components in spring wheat (Triticum aestivum L.) under normal conditions 
Chhibber, S. and Jain, D. 2014. Inter correlation studies among yield and its contributing traits in bread wheat genotypes grown in Haryana, India (Triticum aestivum L.). International Journal of Current Research and Review, Vol. 6 (12): 12

Del Moral, L., Rharrabti, Y., Villegas, D. and Royo, C. 2003. Evaluation of grain yield and its components in durum wheat under Mediterranean conditions. Agronomy Journal, Vol. 95 (2): 266-274

Dewey, D. R. and Lu, K. 1959. A correlation and path-coefficient analysis of components of crested wheatgrass seed production. Agronomy Journal, Vol. 51 (9): 515-518

Donner, D. and Osman, A. 2007. COST860-SUSVAR

Fellahi, Z., Hannachi, A., Bouzerzour, H. and Boutekrabt, A. 2013. Correlation between traits and path analysis coefficient for grain yield and other quantitative traits in bread wheat under semi arid conditions. Journal of Agriculture and Sustainability, Vol. 3 (1): 16

Gelalcha, S. and Hanchinal, R. 2013. Correlation and path analysis in yield and yield components in spring bread wheat (Triticum aestivum L.) genotypes under irrigated condition in Southern India. African Journal of Agricultural Research, Vol. 8 (24): 3186-3192

Iftikhar, R., Khaliq, I., Kashif, M., Ahmad, M. and Ullah, S. 2012. Study of morphological traits affecting grain yield in wheat (Triticum aestivum L.) under field stress condition. Middle-East Journal of Scientific Research, Vol. (11): 19-23

Milligan, S., Gravois, K., Bischoff, K. and Martin, F. 1990. Crop effects on genetic relationships among sugarcane traits. Crop Science, Vol. 30 (4): 927-931

MoAD, 2014. Statistical Information on Nepalese Agriculture 2013/2014. In: DIVISION, A. P. A. S. (Ed.^(Eds.), Government of Nepal, Ministry of Agricultural Development (MoAD), Singha Darbar, Kathmandu.

Mohammadi, M., Sharifi, P., Karimizadeh, R. and Shefazadeh, M. K. 2012. Relationships between grain yield and yield components in bread wheat under different water availability (dryland and supplemental irrigation conditions). Notulae Botanicae Horti Agrobotanici Cluj-Napoca, Vol. 40 (1): 195

Reza Nasri, A. K., Farzad Paknejad, Saeed Vazan and Barary, M. 2014. Correlation, path analysis and stepwise regression in yield and yield component in wheat (Triticum aestivum L.) under the temperate climate of Ilam province, Iran. Indian Journal of Fundamental and Applied Life Sciences, Vol. 4 (4): 188-198

Singh, R. K. and Chaudhary, B. D. 1979. Biometrical methods in quantitative genetic analysis. Biometrical methods in quantitative genetic analysis

Suleiman, A., Nganya, J. and Ashraf, M. 2014. Correlation and path analysis of yield and yield components in some cultivars of wheat (Triticum aestivum L.) in Khartoum State, Sudan. Journal of Forest Products and Industries, Vol. 3 (6): 221-228

Tsegaye, D., Dessalegn, T., Dessalegn, Y. and Share, G. 2012. Genetic variability, correlation and path analysis in durum wheat germplasm (Triticum durum Desf). Agricultural Research and Reviews, Vol. 1 (4): 107-112

Zafarnaderi, N., Aharizad, S. and Mohammadi, S. 2013. Relationship between grain yield and related agronomic traits in bread wheat recombinant inbred lines under water deficit condition. Annals of Biological Research, Vol. 4 (4): 7-11 